\title{
Relação entre significado do trabalho e rotatividade de serventes de limpeza
}

Relation between meaning of work and cleaning worker turnover Relación entre significado del trabajo y rotación de empleados de la limpieza

\author{
Mohana KRUGER Oliveira ${ }^{1, a}$ \\ Amalia Raquel PÉREZ-NEBRA ${ }^{\mathrm{b}}$ \\ Carla Sabrina ANTLOGAc \\ Limpidus, Brasília, DF, Brasil ${ }^{a}$, Centro Universitário de Brasília, Brasília, DF, Brasil ${ }^{\mathrm{b}}$ \\ Universidade de Brasília, Brasília, DF, Brasil
}

Resumo A rotatividade no setor de serviços de limpeza é apontada na literatura como grande problema neste tipo de atividade, mas há poucos estudos sobre significado do trabalho e relação com a rotatividade. Esta pesquisa investigou, por meio de estudo de caso, a relação entre a rotatividade de serventes de limpeza e o significado do trabalho. Realizaram-se dois estudos, com entrevistas individuais semiestruturadas e submetidas à análise de conteúdo. Os resultados apontam maior rotatividade entre homens, relacionada a pouca identificação com o trabalho, falta de reconhecimento, desprezo e invisibilidade social.

Palavras-chave:

Significado do trabalho; rotatividade; serventes de limpeza.

Abstract Turnover in the cleaning service sector is identified in the literature as a major problem in this area of activity, but there are few studies relating meaning of work and turnover. This research investigated the correlation between turnover among cleaning workers and the meaning of work, via a case study. Two studies were conducted using individual semi-structured interviews, which were submitted to content analysis. The results show that turnover is higher among males, based on their lack of identification with the work, low recognition, disdain, and social invisibility.

Keywords:

Meaning of work; turnover; cleaning worker.

Resumen La literatura puntúa que la rotación en el sector de servicios de limpieza es un gran problema en ese tipo de actividad, pero hay pocos estudios sobre el significado del trabajo en relación con la rotación. Este trabajo investigó la relación entre la rotación de empleados de la limpieza y el significado del trabajo utilizando estudio de caso. Se realizaron dos estudios, con entrevistas individuales semiestructuradas y sometidas al análisis de contenido. Los resultados apuntan mayor rotación entre hombres, relacionada con la poca identificación con el trabajo, falta de reconocimiento, desprecio e invisibilidad social.

Palabras-clave:

Significado del trabajo; rotación; empleados de la limpieza. 
$\mathrm{T}$ odos os anos, no Brasil, milhares de pessoas buscam um posto de trabalho no setor de serviços de limpeza, estimando-se que haja mais de 100 mil profissionais nesta categoria (SIEMACO, 2011). Apesar da baixa remuneração, da invisibilidade do trabalho e das altas exigências físicas impostas pelas atividades, o volume de candidatos na empresa em que este estudo foi realizado é elevado (entre 5 e 12 candidatos por vaga). Todavia, há um fato que, se não é completamente desconhecido, é bastante curioso: um grande número de pessoas que ingressa no cargo de servente de limpeza tende a abandonar seu posto de trabalho em pouco tempo, muitas vezes exercendo a mesma função em outra empresa ou até na mesma, posteriormente. Há um alto índice de rotatividade entre os serventes de limpeza, que, de acordo com dados da Associação Brasileira do Mercado de Limpeza Profissional (ABRALIMP, 2014), é de aproximadamente 60\%. Os índices de rotatividade descontada ${ }^{2}$ no setor de serviço brasileiro estão entre 40,2\% e 45,0\% nos últimos 10 anos (DIEESE, 2014).

Entre os serviços mais comumente terceirizados, o setor de conservação e limpeza é o de maior volume: $68,9 \%$ das empresas o terceirizam (DIEESE, 2007). Nesse sentido, questiona-se: existe uma relação entre o significado atribuído ao trabalho de limpeza e o abandono do posto de trabalho? O objetivo deste artigo é analisar as relações entre as representações que trabalhadores de serviços de limpeza têm sobre seu trabalho e a rotatividade. Para tanto, esta pesquisa realizou-se em formato de estudo de caso, permitindo avaliar, em maior profundidade, esse fenômeno.

$\mathrm{Na}$ literatura brasileira, poucos trabalhos têm como tema a rotatividade, conforme observado em levantamento realizado nas principais revistas científicas de psicologia organizacional e administração entre os anos de 2000 e 2015. Entre os escassos artigos que relacionaram rotatividade e psicologia, ressaltam-se os estudos de Ferreira e Freire (2001), sobre custo do trabalho e com base na ergonomia da atividade; de Cardoso, Pinto, Silighini, Montalto e Caolnego (2013), com foco em gestão de pessoas e recrutamento e seleção; de Oliveira e Honório (2014), sobre geração e valores; de Campos e Malik (2008), sobre satisfação no trabalho com médicos; e, ainda, o estudo de Bezerra (1997), que descreve fenômenos psicológicos possivelmente relacionados a rotatividade, mas sem mensurá-los. Analisando-se os artigos mencionados, verifica-se que não foram estabelecidas, pelos autores, relações entre a rotatividade e o significado do trabalho, embora a questão do significado permeie as questões levantadas pelas pesquisas. $\mathrm{Na}$ literatura internacional, encontrou-se apenas um artigo sobre significado do trabalho e rotatividade com trabalhadores de cassino, de Lai, Chan e Lam (2013).

O termo rotatividade "representa a substituição do ocupante de um posto de trabalho por outro, ou seja, a demissão seguida da admissão, em um posto específico, individual, ou em diversos postos, envolvendo vários trabalhadores" (DIEESE, 2011, p. 79). Para Harkins (1998), refere-se à perda de recursos humanos e sua substituição. Considerando-se as definições de rotatividade do DIEESE (2011) e de Harkins (1998), depreende-se que a rotatividade pode ser: (a) planejada e provocada pela organização ou pela pessoa, ou (b) não planejada pela organização ou pela pessoa.

A despeito destas definições, sabe-se que toda rotatividade gera custos. Pesquisas apontam que a reposição de um funcionário pode custar de 93\% a 300\% do seu salário (Davidison, Timo, \& Wang, 2010). Além dos custos financeiros envolvidos na demissão, existem despesas com processos de recrutamento, seleção, contratação e treinamento (Vazifehdust \& Khosrozadeh, 2014).

Em função do caráter multicausal do fenômeno da rotatividade, seu estudo implica desafios tanto práticos, quanto teóricos. Parece pertinente, portanto, analisar categorias mais amplas e apriorísticas, como o significado do trabalho, possibilitando, assim, compreender se a rotatividade pode, eventualmente, ter relação com um trabalho com pouco significado e se há impactos da fragilidade de significado na intenção da pessoa de abrir mão de seu posto de trabalho.

O trabalho pode ser entendido e definido de diversas formas, e a ênfase em um ou outro aspecto é o elemento diferencial nas distintas definições encontradas na literatura (Ros \& Grad, 2005; Salanova, Gracia, \& Peiró, 1996). Via de regra, o trabalho é intencional, pretende um resultado, tem certo caráter de obrigação e é feito para se receber algo em troca (Salanova et al., 1996). Mas tal definição, assim como qualquer outra, pode variar em função da cultura, do grupo social, do olhar epistemológico, da religião e de outros grupos aos quais o sujeito pertença.

\footnotetext{
A taxa de rotatividade descontada refere-se aos casos de morte, aposentadoria, transferência e a pedido do trabalhador. Tais motivações excluem a pessoa do seguro-desemprego.
} 
As dimensões que compõem o significado do trabalho não são consensuais na literatura, apesar de verificarse que grande parte delas está centrada em seus aspectos positivos (cf. Borges \&Yamamoto, 2010; Rosso, Dekas, \& Wrzesniewski, 2010). Também não é consenso a discussão sobre a estabilidade do fenômeno (Salanova et al., 1996). Existe a tese de que o significado do trabalho esteja associado a traços específicos de personalidade e, assim, seria estável ao longo da vida (Pfeffer, 1998). No entanto, há aqueles que defendem que o significado do trabalho seja fruto da experiência laboral e, portanto, um estado (p. ex., Ros \& Grad, 2005). Além disso, há também autores que tentaram aproximar essas duas vertentes teóricas e propõem que o significado do trabalho possa ligar-se profundamente a valores do trabalho e, com isso, relacionar-se à interação entre variáveis de personalidade e ambientais (cf. Salanova et al., 1996).

Algumas linhas de pesquisa propõem que o trabalho tem um significado intrínseco, mas que varia de intensidade conforme a vivência (p. ex., estudo do meaning of work de Harpaz, 1985; Kubo \& Gouvêa, 2012). Outra vertente propõe que a estrutura de significados muda conforme a ocupação (p. ex., supermercadistas e profissionais da construção civil: Borges \& Tamayo, 2001; profissionais da saúde, bancários: Borges \& Alves Filho, 2001; profissionais da saúde, bancários e petroleiros: Borges \& Alves Filho, 2003; psicólogos: Borges \& Yamamoto, 2010). Uma revisão sobre conceitos correlatos e correntes teóricas pode ser encontrada em Bendassolli e Gondim (2014).

Partindo do pressuposto de que não há consenso na literatura, Rosso et al. (2010) apresentaram um modelo integrado de significado do trabalho, que propõe agregar as dificuldades apontadas por diferentes correntes teóricas e parte de princípios básicos pelos quais o mecanismo de significado do trabalho pode ser explicado: autenticidade, autoeficácia, autoestima, propósito de vida, sensação de pertencimento, transcendência e significado cultural ou interpessoal. Tais mecanismos são descritos na Tabela 1.

TABELA 1. Mecanismos, definição e explicações dadas na atuação dos mecanismos.

Mecanismo Definição

Senso de coerência ou alinhamento entre o comportamento e a percepção do verdadeiro eu (self).

Autenticidade

Propósito

Transcendência

Significado cultural ou interpessoal balhador tem valor. de na vida.

Uma forma dominante de manter um número mínimo de relações interpessoais significativas e positivas. além do mundo material. significado que as pessoas têm dos diferentes aspectos do seu trabalho.
Crença do indivíduo sobre seu poder e 1. Sentimento de controle e autonomia;

habilidade para produzir um efeito ou fa- 2 . Reconhecimento de sua competência como resultado da supezer diferença na vida.

3. Percepção do impacto positivo de seu trabalho na organização.

Sentimento de realização, reconhecimento ou afirmação que faz os A avaliação ou estimativa de que o tra- trabalhadores se sentirem valorizados. Diferentemente da autoeficácia, a autoestima não depende da competência do sujeito, mas apenas da valorização.

O senso de propósito guia ideais e dá significado ao ser humano.

Senso de diretividade ou intencionalida- Liga-se a:

1. Significância do propósito;

2. Sistema de valores humanos.

1. Sensação de identificação social com o trabalho;

2. Conexão interpessoal, em que há conforto e suporte.

Conexão ou suplantação do ego para 1. Contribuição com algo inexistente sem esforço coletivo; uma entidade maior que o próprio self ou 2 . Experiência de abnegação ou subordinação a algo maior do que o self.

Forças socioculturais que modelam o É uma explicação que difere das demais por seu nível de análise. oxplicação baseada em self. Aqui, o significado é inerente a uma construção social, definida pelo contexto no qual o indivíduo está inserido.

Rosso et al. (2010) organizaram esses princípios explicativos em quatro quadrantes separados em vias ortogonais, no quais em um polo estão (a) orientação para o self e (b) orientação para os outros; e no outro polo encontram-se (c) orientação para diferenciação e separação, denominado agenciamento e (d) orientação para conexão e unidade, denominado comunhão. Esses quadrantes foram denominados como: com vetores em (a) self e agenciamento, onde se encontram mecanismos de individuação (autoeficácia e autoestima); (b) em self e comunhão, onde se encontram mecanismos de autoconexão (autenticidade); (c) em agenciamento e outros, onde estão os mecanismos de contribuição (propósito [significado] e transcendência); e (d) outros e comunhão, 
onde estão os mecanismos de unificação (propósito [valores] e pertencimento). Essa perspectiva teórica sustenta este estudo e, embora haja outras possibilidades de interpretação para a relação do homem com o trabalho, como a psicodinâmica do trabalho (Dejours, 1992), a perspectiva adotada parece ser a mais pertinente, dado o objetivo da investigação. A fim de fornecer subsídios para uma melhor compreensão do campo de estudo aqui tratado, cabe uma breve explanação sobre o trabalho de limpeza e algumas de suas especificidades que o diferenciam de outras atividades laborais.

Desde que o trabalho sofreu modificações históricas impostas pela Revolução Industrial e foi, aos poucos, expropriado dos sujeitos, os indivíduos livres passaram a ter que vender a única mercadoria que possuíam: sua força de trabalho (Borges \& Yamamoto, 2014). Isso lhes garantia não só inserção na sociedade, mas, acima de tudo, possibilidade de sobrevivência e satisfação de suas necessidades básicas (como alimentação, vestuário, abrigo).

Atualmente, percebem-se os reflexos da reestruturação produtiva (Baumgarten, 2006), caracterizada por modificações nas relações de produção de trabalho e por introdução de novas tecnologias informatizadas. Um dos principais reflexos da reestruturação produtiva, nesse sentido, foi criar uma severa distinção entre trabalhadores qualificados e não qualificados, diferenciando pessoas que trabalham com base, acesso e domínio de tecnologias específicas. Assim, se qualificados, os trabalhadores têm uma gama relativamente maior de situações de trabalho que podem almejar. Por outro lado, quando sua especialização é baixa, via de regra, suas opções tornam-se restritas e, nesse cenário, tarefas de menor valor agregado, tanto em termos sociais, quanto pecuniários, são a alternativa para sua subsistência. Por essas razões, o trabalho de limpeza tende a assumir quase estritamente o significado de algo "que se faz para sobreviver" (Diogo \& Maheirie, 2007), assumindo status de invisibilidade social (Costa, 2004), promovendo vivências de reificação e humilhação social (Costa, 2004; Diogo \& Maheirie, 2007); trabalhar com a sujeira pode ser considerado um trabalho não digno. Apesar de a exposição à sujeira não ser, necessariamente, algo intrinsecamente indigno (p. ex., Ackroyd, 2007), a questão de trabalhar com a sujeira remete, muitas vezes, a uma representação de sujeira moral (p. ex., Ashforth \& Kreiner, 2014; Lai et al., 2013).

De muitas maneiras, verifica-se que, no Brasil, ainda há resquícios de uma concepção de trabalho associada a aspectos dolorosos, degradantes, e a tarefas sacrificantes (Borges \& Yamamoto, 2014), sendo observada também a banalização do mal-estar e do sofrimento no trabalho (Antloga \& Avelar, 2013). O mal-estar e o sofrimento associados ao trabalho podem ser relacionados também a uma tradição católica romana, que se instalou junto com os portugueses no Brasil, e que aborda o sofrimento, o sacrifício e a autonegligência como caminhos para a ascensão espiritual (Borges \& Yamamoto, 2014; Freyre, 2003).

Especificamente no Brasil, o serviço de limpeza carrega um fardo histórico, posto ter sido uma atividade destinada às escravas encarregadas de cuidar da Casa Grande (Freyre, 2003). O status associado a esse tipo de atividade é um elemento central na formação e na percepção da dignidade do trabalho e, no caso do serviço de limpeza, invoca vários tipos de preconceito (Bolton, 2007). Observa-se, assim, que para o imaginário coletivo, o trabalho de limpeza é considerado feminino, não qualificado e subalterno, relembrando ou reproduzindo socialmente o servilismo do período escravista (Bezuidenhout \& Fakier, 2006). Essa herança tem impactos diretos no significado do trabalho e, consequentemente, na construção da identidade social dos trabalhadores (Diogo \& Maheirie, 2007). Define-se identidade social como parte da autoimagem derivada da categoria social na qual o indivíduo se percebe pertencente (Tajfel \& Turner, 1986), com a hipótese central de que há viés intergrupal baseado no desejo de perceber o grupo e a si mesmo de maneira positiva (Brown, 2000; Lai et al., 2013).

A metáfora da Cinderela (Cooper \& May 2007; Herod \& Aguiar, 2006), remetendo ao trabalhador que é mal vestido, com péssimas relações, baixo status, em que raramente se vê a luz do dia e não há príncipe encantado, é cabível para esse caso. O que se pode fazer para se ter um significado do trabalho que seja digno? Há uma balança, descrita por Cooper e May (2007), de escolhas de trabalho entre aqueles de alto risco, precário, sem benefício, mas com alta lucratividade, muito relacionada ao trabalho informal, e a percepção de ser a única oportunidade de ter segurança e sustento, ligada ao trabalho de conservação e limpeza. No Brasil, diferentemente de outros países, esse trabalho é formal e sindicalizado em terceirizados de serviço (cf. Herod \& Aguiar, 2006), apesar de ser menos valorizado que em outros países, como Estados Unidos e parte da Europa. 
Para cumprir o objetivo deste estudo, de apresentar considerações sobre as relações entre representações que trabalhadores de serviços de limpeza têm acerca do significado de seu trabalho e a rotatividade nesse tipo de função, conduziram-se dois estudos consecutivos, ambos com abordagem qualitativa.

\section{MÉTODO}

\section{Contexto da pesquisa}

Todas as entrevistas foram realizadas em uma empresa conhecida pelo nome fantasia Limpidus, que presta serviços de limpeza e conservação em Brasília. A empresa em que foi desenvolvido o estudo é privada e opera com pouco mais de 200 funcionários (32\% de mulheres), conhecidos como terceirizados de serviço e lotados em diversos locais públicos e privados. O trabalho é feito em grupo, havendo um encarregado e uma equipe subordinada a ele. A rotatividade é alta e a empresa encontra dificuldade de contratação de pessoal.

Havia vagas e candidatos, mas não quem estivesse disposto a trabalhar. Em outras palavras, no momento de recrutamento e seleção, havia candidatos, mas quando a seleção ocorria, o candidato não se dispunha a trabalhar no cargo, sequer aparecendo no primeiro dia de trabalho. Outro fenômeno associado era que a maioria dos desistentes era homens (na relação de um para sete, nos recrutamentos dos últimos seis meses) e não havia distinção de idade. Esses foram os problemas iniciais e, a partir deles, dois estudos se desenvolveram, conforme descrito a seguir. A hipótese central para explicar o fenômeno foi a distância entre o significado atribuído ao trabalho, no geral, e o significado atribuído ao cargo de servente de limpeza.

\section{Estudo 1}

O objetivo do estudo 1 foi identificar as principais causas da rotatividade no cargo de servente de limpeza. Realizou-se um estudo exploratório preliminar com candidatos que eram selecionados para o cargo e desistiam da vaga de servente, ou seja, não compareciam no primeiro dia de trabalho. Ao todo, houve 25 desistências no período pesquisado, sendo 21 homens e quatro mulheres. As entrevistas ocorreram por telefone, com tempo variando entre 5 e 7 minutos, com 15 homens e três mulheres. As respostas usualmente refletiam desejabilidade social (horário, "arranjei outra coisa”, etc.). A justificativa relacionada ao baixo salário também esteve presente e duas hipóteses explicativas foram propostas: o salário é central entre os resultados valorizados (Salanova et al., 1996) e, na balança entre poucos benefícios e alta lucratividade (p. ex., trabalho informal), ou benefícios e segurança (trabalho formal) (Cooper \& May, 2007), preferiu-se o primeiro.

Estabeleceu-se também uma hipótese explicativa alternativa: em vez de revelar outras causas relacionadas à natureza da atividade (Costa, 2004), o participante preferia responder que o salário não o satisfazia, dado próximo aos achados da pesquisa de Bezerra (1997). Outro fenômeno observado foi a disparidade entre homens e mulheres: é mais fácil para o homem conseguir outro emprego ou trabalho com melhor remuneração; no caso das mulheres, o salário de auxiliar de serviços gerais é mais próximo à média. ${ }^{3}$ Tal disparidade de gênero foi encontrada tanto no estudo preliminar quanto no quadro geral de funcionários da empresa.

\section{Participantes}

Participaram desta pesquisa 8 homens e 3 mulheres, selecionados por conveniência e que trabalhavam na empresa na data da entrevista. O único critério para a escolha dos participantes foi ocupar o cargo de auxiliar de serviços gerais (servente de limpeza).

\section{Instrumento}

A coleta de dados realizou-se por meio de entrevista individual semiestruturada. A escolha desta abordagem deu-se em função da hipótese central referente à diferença entre os significados do trabalho, em que interessava a qualidade do discurso, bem como a acessibilidade, relacionada a sua frequência. Outro motivo foi a dificuldade dos participantes em produzir relatos escritos, dado o baixo nível instrucional.

\footnotetext{
Na Convenção Coletiva de Trabalho do DF de 2015, registrada no Ministério do Trabalho e Emprego, definiu-se o salário de auxiliar de serviços gerais em $R \$ 952,22$ e o ticket alimentação em $R \$ 24,00$ por dia trabalhado, com 22 dias trabalhados significa $R \$ 1.480,22$. Segundo a última Pesquisa de Emprego e Desemprego (PED) realizada pelo DIEESE contendo o DF, o rendimento médio mensal dos homens em 2013 foi de $\mathrm{R} \$ 2.598,00$ e das mulheres de $\mathrm{R} \$ 1.914,00$.
} 


\section{Procedimentos de coleta de dados e cuidados éticos}

Inicialmente, contatou-se o encarregado do posto para solicitar autorização. Este, em conversa com os trabalhadores, verificou seu interesse em participar e agendou o encontro no próprio local de trabalho, trinta minutos antes do término do expediente. As perguntas versaram sobre a rotina de trabalho, o significado do trabalho e as diferenças de gênero percebidas, identificadas no estudo preliminar.

As entrevistas duraram aproximadamente 20 minutos e foram realizadas no próprio ambiente de trabalho, em um espaço privativo, devendo-se esta escolha à dificuldade de marcar um encontro com os participantes em outro horário/local. Todas as entrevistas foram gravadas, mediante prévia autorização, transcritas e submetidas à análise de conteúdo.

\section{Procedimentos de análise dos dados}

As entrevistas transcritas foram submetidas à análise de conteúdo categorial, como proposto por Bardin (1977). Este modelo organiza a análise de conteúdo em três fases: pré-análise, que inclui leitura flutuante, escolha dos documentos, preparação do material e elaboração de indicadores; exploração do material e, por último, tratamento dos resultados, inferência e interpretação. De acordo com Bardin (1977), a análise de conteúdo consiste em descobrir os núcleos de sentido que compõem a comunicação e cuja frequência de aparição pode ter significado para o objetivo proposto. Dois pesquisadores fizeram a análise separadamente e, em momento posterior, reuniram-se para sanar as divergências. Para este estudo, seguiu-se, na medida do possível, a proposta de Bardin (1977), apresentando o conteúdo e também a frequência de sua aparição.

\section{RESULTADOS E DISCUSSÃO PARCIAL}

A análise de conteúdo resultou nas categorias Significado do trabalho, Classificação e atividades do trabalho e Características de gênero no trabalho. A primeira categoria compreende o papel do trabalho na vida desses trabalhadores; a segunda, Classificação e atividades do trabalho, representa a avaliação qualitativa das atividades executadas nessa profissão. A última categoria está relacionada às diferenças entre homens e mulheres relatadas no ambiente de trabalho.

\section{Categoria 1 - Significado do trabalho (Frequência = 13)}

As respostas obtidas nesta categoria foram diversificadas; verifica-se que, para os participantes, o trabalho tem como mecanismo de construção de seu significado o seu propósito, antes de tudo, de sustento/sobrevivência (cf. Costa, 2004; Diogo \& Maheirie, 2007; Salanova et al., 1996). Entretanto, para os entrevistados, o trabalho ultrapassa a questão da sobrevivência e passa a ser fonte de prazer, similar aos achados de pesquisa de Borges (2005), Dejours (1992) e ao conceito de produção de significado, relatado na pesquisa de Ashforth e Kreiner (2014). O trabalho, além de atender necessidades materiais, é fonte de prazer, realização e conquista, ligado, portanto, aos mecanismos de individuação: autoeficácia e autoestima para construção do significado (Rosso et al., 2010) e com significado positivo.

Para as mulheres, representa sua saída de casa, tanto para ganhar espaço no mercado de trabalho, quanto para exercer sua dignidade. Assim, de acordo com uma participante (34 anos):

Sem o meu trabalho me sentiria desmotivada pra tudo. Dá motivo bom pra gente, né? ...como mulher por exemplo, sair pra trabalhar, né? ...levanta a autoestima da pessoa, né? ...como mulher, dona de casa. Então você sai, levanta cedo sabendo: "hoje eu vou pro meu trabalho". Pra mim é um ganho de vida... material, espiritual, né? Eu me sinto digna trabalbando.

Novamente, o trabalho deixa de representar somente uma forma de sustento/sobrevivência, apesar do seu destaque nas respostas, e tem seu significado ampliado para uma forma de manutenção da saúde e segurança do indivíduo e de sua família para além do consumo. Tais achados se aproximam do que Borges (2005) encontrou em sua pesquisa de valores e ao que Rosso et al. (2010) apontaram no mecanismo de significado relacionado ao propósito do trabalho, e ligados aos valores humanos, situando-se, portanto, no quadrante relacionado à unificação.

Outros temas qualitativamente importantes se mostraram presentes nas entrevistas, embora com menor frequência: reconhecimento social, motivação, realização e ocupação. Estes temas também foram encontrados 
em outros trabalhos relativos ao serviço terceirizado (p. ex., Cerqueira \& Pérez-Nebra, 2013; Costa, 2004; Diogo \& Maheirie, 2007) e centram-se no quadrante de individuação e autoconexão, descritos por Rosso et al. (2010).

\section{Categoria 2 - Classificação das atividades do trabalho (Frequência = 11)}

Ao serem questionados sobre como avaliavam, no geral, o serviço de limpeza, os participantes consideraram a carga de trabalho moderada. As respostas dos homens tiveram como parâmetro o trabalho executado na construção civil. Para as mulheres, o serviço também foi percebido como de exigência moderada, especialmente se comparado com o trabalho doméstico, como declarou uma participante, ao afirmar que "você tem que limpar, passar, cozinhar, cuidar de menino e não tem hora pra sair" (D. Mulher, 37 anos). O trabalho assalariado pode se tornar pesado na medida em que o tempo para a execução das tarefas não é suficiente.

As referências ao serviço pesado estão relacionadas a lavagem de piso e a atividade de descer e subir escadas ou rampas com baldes de água e carrinho cheio de lixo. Tanto os homens quanto as mulheres consideraram a lavagem de piso a atividade mais pesada do serviço de limpeza, pois requer mais tempo e a utilização de uma máquina pesada.

\section{Categoria 3 - Características de gênero no trabalho (Frequência = 8)}

Tendo em vista o objetivo deste estudo, verifica-se que esta categoria contém elementos que podem apontar indícios que permitam compreender o fenômeno proposto. Nas respostas dos participantes, identificaram-se características femininas e masculinas que os separam na profissão. Por exemplo, atenção aos detalhes e delicadeza foram identificadas como características do trabalho feminino. No trabalho masculino, relataram-se objetividade e capacidade de lidar com tarefas que necessitem de força física (Hofstede, Hofstede, \& Minkov, 2010).

Nota-se que na empresa há uma divisão de tarefas marcada por gênero: as mulheres são responsáveis pelo serviço delicado e os homens pelo serviço pesado. Tal divisão pode ser atribuída ao reflexo das representações discursivas de gênero da sociedade, em que o homem representa força e virilidade e, a mulher, fragilidade e delicadeza (Acevedo, Tamashiro, Nohara, \& Cunha, 2013). Logo, na empresa, delega-se aos homens a lavagem de piso, o recolhimento de lixo, a varrição externa; às mulheres, a limpeza de salas, a lavagem dos panos e a limpeza de banheiros.

Os entrevistados atribuem a alta rotatividade dos homens ao preconceito que sofrem por trabalharem nessa função, originalmente destinada às mulheres. Como declarou um participante, "preconceito, só isso. Preconceito de estar trabalhando na limpeza" (M. Homem, 31 anos). Para Costa (2004), o fenômeno pode ser interpretado também como humilhação social, humilhação automatizada e relacionado ao preconceito e à discriminação (cf. Pérez-Nebra \& Jesus, 2011). Nesse sentido, pode-se questionar sobre a referência do preconceito experimentado: seria um preconceito sobre si mesmo? Seria o significado desse tipo de trabalho relacionado à sua rejeição? As pessoas sairiam da empresa para buscar, portanto, trabalhos menos invisíveis, com menor humilhação social e com um significado diferente? Essas perguntas nortearam a condução do segundo estudo, apresentado a seguir.

\section{Estudo 2}

O objetivo do estudo 2 foi analisar a relação estabelecida entre o significado geral do trabalho, o significado atribuído ao serviço de limpeza e o índice de rotatividade na função de servente de limpeza.

\section{Participantes}

Participaram deste estudo dez homens e dez mulheres, selecionados por conveniência, com idades variadas, pois, diferentemente de outros estudos (Bezerra, 1997; Oliveira \& Honório, 2014), esta variável não foi significativa. O único critério para a escolha dos participantes foi trabalhar na empresa no cargo de auxiliar de serviços gerais.

\section{Instrumento}

A coleta de dados foi realizada por meio de entrevistas individuais semiestruturadas, tal qual no estudo 1. Neste estudo, as perguntas versaram sobre o significado do trabalho; o porquê da opção pelo trabalho de auxiliar de serviços gerais; a importância desse serviço; as percepções dos trabalhadores e dos outros sobre esse 
trabalho e, por fim, os possíveis preconceitos direcionados a essa atividade. As perguntas tiveram por referência o estudo de Borges e Peixoto (2011).

\section{Procedimentos de coleta de dados e cuidados éticos}

As entrevistas foram realizadas no próprio local de trabalho, antes dos participantes encerrarem o expediente de trabalho, procedimento similar ao do estudo 1. As entrevistas duraram aproximadamente 30 minutos.

\section{Procedimentos de análise dos dados}

A análise dos dados seguiu o modelo de Bardin (1977), conforme descrito no estudo 1.

\section{RESULTADOS E DISCUSSÃO PARCIAL}

A análise de conteúdo gerou três categorias: Significado do trabalho, Fatores motivacionais e Rotatividade.

\section{Categoria 1 - Significado do trabalho (Frequência = 75)}

Assim como nos resultados do estudo 1, o trabalho supera sua função de sustento/sobrevivência e assume diversas representações na vida dos indivíduos. Neste estudo, surgiram novos exemplos que reforçam a complexidade de pensar a dinâmica do trabalho na sociedade. Desse modo, a categoria foi dividida em cinco temas: necessidades de primeira ordem, relação com a sociedade e história de vida, percepção do trabalho pelo trabalhador e percepção do trabalho pelo outro. Necessidades de primeira ordem estão relacionadas a sustento e sobrevivência. Relação com a sociedade refere-se à honestidade, ao reconhecimento social e ao poder de consumo. História de vida apresenta falas relacionadas à conquista, à independência financeira, à realização, à liberdade. Percepção do trabalho pelo trabalhador relaciona-se à autoestima e percepção do trabalho pelo outro se relaciona à avaliação do trabalho como algo degradante.

Quanto ao significado do trabalho, todos os quadrantes de significado do trabalho surgem: autoconexão, individuação, contribuição e unificação. A primeira resposta que emerge é sustento e sobrevivência, situada no quadrante de contribuição, similar ao que apareceu no estudo 1. O prazer e o reconhecimento social (quadrantes de individuação e autoconexão) aparecem com menor frequência. $\mathrm{O}$ trabalho pode assumir significados diversos em função do momento social em que se vive. Por exemplo, quanto mais a sociedade valoriza o consumo, mais valorizado será o trabalho e mais digno e merecedor de respeito será aquele que trabalha e tem sucesso, posto que ele conseguiu inserção social (Ashforth \& Kreiner, 2014).

Em entrevista alguma houve atribuição de significado negativo ao trabalho, o que pode ser resultado de uma desconfiança com relação ao objetivo da pesquisa, ou o que a literatura tem apontado de que o significado tem uma valência positiva nele mesmo (cf. Borges \& Yamamoto, 2010; Rosso et al., 2010) ou mecanismos de resistência ao adoecimento (Dejours, 1992). Entretanto, quando o assunto sai da generalidade do trabalho e passa para a especificidade da profissão, os resultados se mostram coerentes com a hipótese do trabalho, na medida em que a profissão tem, para a sociedade, um significado específico, relativo, como mencionado anteriormente, a um trabalho socialmente desvalorizado (Ashforth \& Kreiner, 2014).

Nota-se também que os quadrantes de contribuição e unificação, ligados à percepção de impacto do trabalho, ao propósito e a interconexão, emergem aqui na percepção do trabalho pelo trabalhador e na percepção do trabalho pelo outro. $\mathrm{O}$ trabalho na limpeza é visto pelo próprio trabalhador como destinado às pessoas que não têm estudo e acaba sendo a última opção do indivíduo para sobreviver. Entretanto, a percepção dos trabalhadores entrevistados é mais ampla, e não apenas negativa. Para os entrevistados, essa atividade desempenha um papel social importante, relacionando-se à limpeza, à higienização e ao bem-estar alheio, além de bom funcionamento organizacional, avaliações também encontradas por Ashforth e Kreiner (2014).

A percepção de falta de reconhecimento é um aspecto marcante nas entrevistas, posto que os trabalhadores se percebem invisíveis (Costa, 2004; Diogo \& Maheirie, 2007). O reconhecimento está vinculado principalmente ao quadrante de mecanismos ligados à individuação, ou seja, de autoeficácia e autoestima. O não reconhecimento do trabalho e a desvalorização do próprio profissional que o executa gera sentimentos de tristeza, raiva, inferioridade, decepção e, muitas vezes, vergonha. O mesmo trabalho que constrói a identidade destrói a integridade do indivíduo, o que pode ser percebido na fala de um participante, ao afirmar que "julgam a gente pelo que a gente faz (...) muitas vezes olham a gente assim... como uns nojentos, uns fedidos... chamam a gente de lixeira, 
de lixo" (M. Mulher, 38 anos); "as pessoas têm que enxergar as pessoas que cuidam da limpeza como ser humano igual a ele, de que ele tá lá, ele existe, de que ele merece respeito, de que ele merece atenção" (E. Homem, 34 anos).

Nota-se uma ambiguidade durante as entrevistas: há momentos em que o trabalho é fonte de orgulho; em outros, gera vergonha, dando suporte à hipótese da diferença entre o significado geral do trabalho e o significado atribuído à categoria. Essa dinâmica pode ser entendida por meio da teoria da identidade social, para a qual os indivíduos buscam uma identidade social positiva fazendo parte de grupos sociais que agreguem valor e significado emocional, sugerindo a pertença a grupos sociais de maioria (Ashforth \& Kreiner, 2014; Brown, 2000; Lai et al., 2013). Entretanto, essa avaliação e busca por uma identidade social positiva parte de uma comparação a alguma referência (Brown, 2000), que pode gerar discrepância positiva ou negativa a depender de qual parâmetro está sendo utilizado. As discrepâncias a referenciais pode ser uma explicação da dinâmica que se evidencia nas entrevistas, pois, dependendo do grupo de comparação, o trabalho pode ser fonte de orgulho ou de vergonha (Brown, 2000).

Mazón, Espelt e Rodríguez-Carballeira (2007) sugerem que a pertença a uma identidade social de minoria (de baixo status) tende a fazer os indivíduos se fecharem em grupos com a mesma identidade, criando uma minicultura, em que têm um lugar digno e não são depreciados. Entretanto, quando a identidade social é insatisfatória, há respostas de proteção da identidade, manifestando-se em táticas utilizadas pelos indivíduos, como abandonar o grupo, deixar de identificar-se, redefinir as dimensões de comparação ou contestar o grupo dominante (Brown, 2000; Tajfel \& Turner, 1986). Tais estratégias podem explicar, em parte, o alto índice de rotatividade encontrado tanto na empresa quanto no setor.

Os significados encontrados referem-se tanto ao quadrante unificação quanto a contribuição, estando, assim, relacionados à dimensão do outro na construção do significado do trabalho. Enquanto a sociedade valoriza aqueles que conquistam as coisas por meio do trabalho, qualquer trabalho é sinônimo de dignidade; mas, quando alguns trabalhos são vistos como inferiores e degradantes, geram sentimentos de desprezo, e não de pertencimento.

\section{Categoria 2 - Fatores motivacionais (Frequência = 52)}

A escolha por uma profissão muitas vezes está relacionada à carreira que o indivíduo pretende seguir ou às oportunidades que surgem no mercado de trabalho. Entretanto, para uma parcela da população, o principal fator que influencia essa escolha é justamente a falta de opção, como relatado na literatura (p. ex., Borges \& Yamamoto, 2014; Diogo \& Maheirie, 2007). Entre os entrevistados, somente uma mulher afirmou ter escolhido essa profissão porque efetivamente gostava, quatro avaliaram o emprego como uma boa oportunidade que surgiu e os demais atribuíram à baixa escolaridade a razão de estarem trabalhando na limpeza (como descrito em Diogo \& Maheirie, 2007).

O trabalho na limpeza é visto como uma oportunidade de melhoria para dois grupos de trabalhadores: os que nunca tiveram os benefícios da formalização do trabalho e as mulheres que já trabalharam como empregadas domésticas (Cooper \& May, 2007). Para o primeiro grupo, "trabalhar fichado" representa uma conquista de direitos; para o segundo, o trabalho na limpeza representa fazer basicamente as mesmas atividades, mas com horários de entrada e saída definidos, férias programadas e recolhimento do Fundo de Garantia por Tempo de Serviço.

\section{Categoria 3 - Rotatividade (Frequência = 47)}

Esta categoria é composta pelos principais fatores que levam os funcionários a saírem da empresa e as hipóteses que explicam a elevada rotatividade masculina, em relação à feminina, na organização. Nas entrevistas, a primeira resposta relacionava-se ao baixo salário e, assim, hipotetizou-se a ocorrência de desejabilidade social. Desde o início da pesquisa, verificou-se o elevado número de homens que compunha o quadro de funcionários da empresa. Esse dado foi discutido no estudo 1, em que se levantou a hipótese de um viés na seleção de pessoal da empresa, devido às atividades desempenhadas no trabalho.

Os trabalhadores do sexo masculino buscam ascensão profissional, progredindo para agente patrimonial. ${ }^{4}$ Por sua vez, as mulheres estão a procura de um posto como copeira ou recepcionista. Dos três cargos citados, somente o salário do agente patrimonial é pouco superior ao de servente de limpeza, o que não justificaria a

\footnotetext{
${ }_{4}$ O agente patrimonial é popularmente conhecido como porteiro. O salário, de acordo com a Convenção Coletiva de Trabalho, é de $R \$ 1.037,00$, soma-se $R \$ 528,00$ de ticket alimentação, totalizando $R \$ 1.565,00$, diferença de aproximadamente $5 \%$ de salário entre as categorias.
} 
rotatividade, sugerindo outras hipóteses explicativas para esse fenômeno. Contudo, apoia-se a hipótese do preconceito do próprio trabalhador com o seu trabalho, que é socialmente visto como degradante, em comparação com outras atividades mais reconhecidas (Borges \& Peixoto, 2011). Outra hipótese explicativa é o significado do trabalho, que apresenta pouca possibilidade de desenvolver os mecanismos ligados à individuação ou à autoconexão, ambos os quadrantes direcionados ao self. Por não ser uma profissão reconhecida e, muitas vezes, sendo desprezada pelo outro, os profissionais da limpeza reproduzem esse sentimento e classificam o seu trabalho como a última opção de emprego, havendo uma constante busca por um trabalho melhor, que os tire da margem da sociedade e que ofereça reconhecimento.

Quanto à rotatividade masculina, os entrevistados entendem que os homens saem mais que as mulheres do setor de limpeza por ainda vigorar a cultura machista em que a limpeza é percebida como tarefa de mulher. Também apontam que há mais oportunidades de emprego para os homens, muitas delas na construção civil. Alguns ainda avaliam que os homens não têm a mesma força de vontade que as mulheres para exercer essa função, que é tão desgastante fisicamente.

Em função da demanda de emprego com melhor remuneração no mercado, há maior evasão dos trabalhadores homens, o que gera rotatividade, ainda que esta não se limite a eles, o que reforça a hipótese central de que o significado geral do trabalho distancia-se do significado atribuído à categoria de serventes de limpeza. Nota-se que a política de recrutamento e seleção da empresa não está adaptada à dinâmica do mercado e nem à percepção de quem executa a tarefa.

Diante da falta de reconhecimento, da desvalorização e do preconceito com a profissão, somado à oferta de emprego, os homens buscam, constantemente, qualquer trabalho que possibilite sair da limpeza (Cooper \& May, 2007). As mulheres também sofrem com o desprezo advindo da profissão, mas para elas há menos opções e a aceitação pode ser maior, pois, como mencionou um participante, "mulher já nasce limpando" (A. Mulher, 43 anos) e, dessa forma, é mais aceito ver uma mulher exercendo este trabalho.

\section{DISCUSSÃO GERAL}

O objetivo desta pesquisa foi analisar a relação entre o significado do trabalho e o índice de rotatividade na função de servente de limpeza. A hipótese central foi a de que o significado geral do trabalho distanciavase do significado específico do trabalho de servente de limpeza. Para cumprir o objetivo, foram realizados dois estudos complementares. Com o estudo 1, foi possível descrever de forma exploratória as explicações da rotatividade no trabalho, que estariam ligadas às diferenças de gênero, e chegar à hipótese de que a preferência pela contratação de trabalhadores homens refletia a cultura da organização. Porém, durante as entrevistas, surgiu um aspecto que embasou outra hipótese explicativa da rotatividade: a distância entre os significados do trabalho associada ao preconceito contra a profissão.

Assim, fez-se necessário um segundo estudo para analisar a influência do significado do trabalho na rotatividade. No estudo 2, verificou-se que a forma como a profissão de auxiliar de serviços gerais é percebida na sociedade impacta na rotatividade. A hipótese para a maior participação masculina no índice de rotatividade da função de servente de limpeza é a representação de gênero que permeia o imaginário social, no qual as atividades de limpeza são consideradas femininas (Bezuidenhout \& Fakier, 2006). Apesar da validade da hipótese, fatores como falta de reconhecimento, desprezo e invisibilidade social da profissão levam os funcionários a buscarem alternativas no mercado, dando suporte a hipótese geral desta pesquisa.

Verifica-se também que os mecanismos de significado do trabalho utilizados pelos serventes de limpeza não se relacionam ao self e as suas dimensões de individuação e autoconexão. Pelo contrário, esse significado ocorreu por mecanismos relacionados aos outros, referindo-se às dimensões de contribuição e unificação e seus elementos: percepção de impacto do trabalho, transcendência, propósito de vida relacionado aos valores e significância e, finalmente, sensação de pertencimento. Considerar o significado do trabalho como relativo ao outro pode indicar caminhos diversos para o processo de recrutamento e seleção, além de oferecer elementos para trabalhar a manutenção desses funcionários na organização, bem como procurar valorizar os mecanismos relacionados ao self.

Este estudo pretendeu contribuir, em termos acadêmicos, para diminuir a lacuna referente a estudos e dados relacionados a cargos operacionais com baixa remuneração e baixa escolaridade, que representam uma enorme parcela dos trabalhadores brasileiros. Buscou-se, também, aproximar a psicologia do trabalho e o 
fenômeno da rotatividade para propor possíveis intervenções que beneficiem tanto a organização, quanto os indivíduos que nela trabalham. Entende-se que este objetivo foi cumprido.

Este trabalho também pretendeu agregar, em termos teóricos, o mapeamento de diferentes mecanismos de significado do trabalho construídos pelo trabalhador de serviço de limpeza. Nesse caso, apenas os mecanismos de transcendência e significado cultural não emergiram. Outros apareceram tanto com valência positiva quanto com valência negativa, ainda que as positivas tenham preponderado.

A falta de um espaço mais adequado para a realização das entrevistas e a utilização de um único método pode ter limitado o aparecimento de outros conteúdos, ainda que o uso de métodos mistos com (semi) analfabetos seja um desafio. Apesar disso, foi possível identificar questões que permitem atuar na diminuição do índice de rotatividade, como priorizar os perfis que percebam essa profissão como uma oportunidade e não como a "ültima op̧ção".

No que se refere aos trabalhadores, é necessário desenvolver projetos de intervenção em parceria com os clientes diretos e indiretos para conscientizá-los da importância do papel desses trabalhadores "invisíveis" no ambiente, para que haja valorização, reconhecimento e respeito pela categoria profissional.

A limpeza, por seu caráter servil e de lida com o lixo - aquilo que é descartável -, é vista como última opção de trabalho para muitos. Diante disso, verifica-se que novos estudos são necessários, para que se investiguem formas de realizar gestão de pessoas para uma profissão que, apesar de essencial, é vista como degradante e constantemente descartada, e para que se avalie como seria possível valorizar outros mecanismos de significado do trabalho que não emergiram aqui.

\section{REFERÊNCIAS}

Acevedo, C. R., Tamashiro, H., Nohara, J. J., \& Cunha, J. (2013). Roles portrayed by women: A content analysis in brazilian television advertisement. Journalism and Mass Communication, 3(7), 409-421.

Ackroyd, S. (2007). Dirt, work and dignity. In S. C. Bolton (Ed.), Dimensions of dignity at work (pp. 30-49). Oxford: ButterworthHeinemann.

Antloga, C. S., \& Avelar, R. (2013). Mal-estar no trabalho. In F. O. Vieira, A. M. Mendes \& A. R. C. Merlo (Org.), Dicionário crítico de gestão e psicodinâmica do trabalho (pp. 243-248). Curitiba: Juruá.

Ashforth, B. E., \& Kreiner, G. E. (2014). Dirty work and dirtier work: Differences in countering physical, social and moral stigma. Management and Organizational Review, 10(1), 81-108. doi: 10.1111/more.12044

Associação Brasileira do Mercado de Limpeza Profissional. (2014). Rotatividade de vagas na economia formal manteve alta em 2013. Disponível em: http://abralimp.org.br/modulos/noticias/descricao.php?cod=2345

Bardin, L. B. (1977). Análise de conteúdo. Lisboa: Edições 70.

Baumgarten, M. (2006). Reestruturação produtiva e industrial. In A. D. Cattani \& L. Holzmann (Org.), Dicionário trabalho e tecnologia (pp. 237-239). Porto Alegre: Ed. UFRGS.

Bendassolli, P. F., \& Gondim, S. M. G. (2014). Significados, sentidos e função psicológica do trabalho: Discutindo essa tríade conceitual e seus desafios metodológicos. Avances en psicología latino-americana, 32(1), 131-147.

Bezerra, A. L. Q. (1997). O significado da rotatividade de pessoal numa instituição de saúde privada. Revista Brasileira de Enfermagem, 50(1), 107-120.

Bezuidenhout, A., \& Fakier, K. (2006). Maria's Burden: Contract cleaning and the crisis of social reproduction in post-apartheid South África. Antipode, 38(3), 462-485. doi: 10.1111/j.0066-4812.2006.00590.x

Bolton, S. C. (2007). Dignity in and at work: Why it matters. In S. C. Bolton (Ed.), Dimensions of dignity at work (pp. 3-16). Oxford: Butterworth-Heinemann.

Borges, L. O. (2005). Valores de trabalhadores de baixa renda. In Á. Tamayo \& J. B. Porto (Orgs.), Valores e comportamento nas organizações (pp. 233-250). Petrópolis: Vozes.

Borges, L. O., \& Alves Filho, A. (2001). A mensuração da motivação e do significado do trabalho. Estudos em Psicologia, 6(2), 177-194.

Borges, L. O., \& Alves Filho, A. (2003). A estrutura fatorial do inventário do significado e motivação do trabalho, IMST. Avaliação Psicológica, 2(2), 123-145.

Borges, L. O., \& Peixoto, T. P. (2011). Ser operário da construção civil é viver a discriminação social. Revista Psicologia: Organizações e Trabalho, 11(1), 21-36. 
Borges, L. O., \& Tamayo, Á. (2001). A estrutura cognitiva do significado do trabalho. Revista Psicologia: Organizações e Trabalho, 1(2), 11-44.

Borges, L. O., \& Yamamoto, O. H. (2010). O significado do trabalho para psicólogos brasileiros. In A. V. B. Bastos \& S. M. G. Gondim (Orgs.), O trabalho do psicólogo no Brasil (pp. 248-282). Porto Alegre: Artmed.

Borges, L. O., \& Yamamoto, O. H. (2014). Mundo do trabalho: Construção histórica e desafios contemporâneos. In J. C. Zanelli, J. E. Borges-Andrade \& A. V. B. Bastos (Orgs.), Psicologia, organizações e trabalho no Brasil (pp. 24-62). Porto Alegre: Artmed.

Brown, R. (2000). Social identity theory: Past achievements, current problems and future challenges. European Journal of Social Psychology, 30, 745-778. doi: 10.1002/1099-0992(200011/12)30:6<745::AID-EJSP24>3.0.CO;2-O

Campos, C. V. A., \& Malik, A. M. (2008). Satisfação no trabalho e rotatividade dos médicos do Programa de Saúde da Família. Revista de Administração Pública, 42(2), 347-368.

Cardoso, L. M., Pinto, S. O., Silighini, C. K., Montalto, V. F., \& Calonego, M. (2013). Recrutamento e seleção de empacotadores em uma rede de supermercados. Estudos Interdisciplinares em Psicologia, 4(1), 110-117.

Cerqueira, F. B. P., \& Pérez-Nebra, A. R. (2013). Significado do trabalho para mulheres de serviços terceirizados de limpeza. Anais do XXXIV Congresso Interamericano de Psicologia (pp. 1086-1087). Brasília: Centro Universitário de Brasília. Recuperado de http://sip2013.sipsych.org/pdf/AnaisCIP-VrsFinal04.pdf

Cooper, N., \& May, C. (2007). The informal economy and dignified work. In S. C. Bolton (Ed.), Dimensions of dignity at work (pp. 88-105). Oxford: Butterworth-Heinemann.

Costa, F. B. (2004). Homens invisíveis: Relatos de uma humilhação social. São Paulo: Globo.

Davidison, M., Timo, N., \& Wang, Y. (2010). How much does labour turnover cost? A case study of Australian four-and five-star hotels. International Journal of Contemporary Hospitality Management, 22(4), 451-466. doi: 10.1108/09596111011042686.

Dejours, C. (1992). A loucura do trabalho: Estudo de psicopatologia do trabalho. São Paulo: Cortez-Oboré.

Departamento Intersindical de Estatística e Estudos Socioeconômicos. (2007). O processo de terceirização e seus efeitos sobre os trabalhadores no Brasil. São Paulo: DIEESE.

Departamento Intersindical de Estatística e Estudos Socioeconômicos. (2011). Rotatividade e flexibilidade no mercado de trabalho. São Paulo: DIEESE.

Departamento Intersindical de Estatística e Estudos Socioeconômicos. (2014). Rotatividade e políticas públicas para o mercado de trabalho. São Paulo: DIEESE.

Diogo, M. F., \& Maheirie, K. (2007). De balde e vassoura na mão: Os sentidos que mulheres serventes de limpeza atribuem aos seus trabalhos. Revista mal-estar e subjetividade, 7(2), 557-579.

Ferreira, M. C., \& Freire, O. N. (2001). Carga de trabalho e rotatividade na função de frentista. Revista de Administração Contemporânea, 5(2), 175-200.

Freyre, G. (2003). Casa-Grande \& Senzala: Formação da família brasileira sob o regime da economia patriarcal (48a ed.). São Paulo: Global.

Harkins, P. J. (1998). Why employees stay or go. Workforce, 77(10), 74-78.

Harpaz, I. (1985). Meaning of working profiles of various ocupational groups. Journal of Vocational Behavior, 26(1), 25-40. doi: 10.1016/0001-8791(85)90023-5

Herod, A., \& Aguiar, L. L. M. (2006). Introduction: Cleaners and the dirty work of neoliberalism. Antipode 38(3), 425-434. doi: 10.1111/j.0066-4812.2006.00587.x

Hofstede, G., Hofstede, G. J., \& Minkov, M. (2010). Cultures and organizations: Softwares of the mind (3a ed.). New York: McGraw-Hill.

Kubo, S. H., \& Gouvêa, M. A. (2012). Análise de fatores associados ao significado do trabalho. Revista de Administração, 47(4), 540-554. doi: 10.5700/rausp1057

Lai, J. Y. M., Chan, K. W., \& Lam, L. W. (2013). Defining who you are not: The roles of moral dirtiness and occupational and organizational disidentification in affecting casino employee turnover intention. Journal of Business Research, 66(9), 16591666. doi: 10.1016/j.jbusres.2012.12.012

Mazón, F. J., Espelt, E., \& Rodríguez Carballeira, Á. (2007). Comportamiento colectivo y movimentos sociales en la era global. In J. F. Morales, M. C. Moya, E. Gaviria \& I. Cuadrado (Coords.), Psicología social (3a ed., pp. 641-691). Madrid: McGrawHill. 
Ministério do Trabalho e Emprego. (2015). Convenção coletiva. Brasília: MTE. Recuperado de http://www.seac-df.com.br/wpcontent/uploads/2015/11/CCT-Sistema-Mediador_DF000131-2015_09-02-2015.pdf

Oliveira, L. B., \& Honório, S. R. F. S. (2014). Atração e desligamento voluntário de jovens empregados: Um estudo de caso no setor jornalístico. Revista de Administração, 49(4), 714-730. doi: 10.5700/rausp1179

Pesquisa de Emprego e Desemprego. (2013). A inserção da mulher no mercado de trabalho. São Paulo: DIEESE. Recuperado de www.dieese.org.br/analiseped/2013/2013pedmulhermet.pdf

Pérez-Nebra, A. R., \& Jesus, J. G. (2011). Preconceito, estereótipo e discriminação. In C. V. Torres \& E. R. Neiva (Orgs.), Psicologia social: Principais temas e vertentes (pp. 217-237). Porto Alegre: Artmed.

Pfeffer, J. (1998). Understanding organizations: Concepts and controversies. In D. T. Gilbert, S. T. Fiske \& G. Lindzey (Eds.), The handbook of social psychology (4a ed., pp. 747-777). Boston: McGraw-Hill.

Ros, M., \& Grad, H. (2005). O significado do valor trabalho relacionado à experiência ocupacional: Uma comparação entre professores primários e estudantes do CAP. In Á. Tamayo \& J. B. Porto (Orgs.), Valores e comportamento nas organizações (pp. 251-279). Petrópolis: Vozes.

Rosso, B. D., Dekas, K. H., \& Wrzesniewski, A. (2010). On the meaning of work: A theoretical integration and review. Research in Organizational Behavior, 30, 91-127. doi: 10.1016/j.riob.2010.09.001

Salanova, M., Gracia, F. J., \& Peiró, J. M. (1996). Significado del trabajo y valores laborales. In J. M. Peiró \& F. Prieto (Eds.), Tratado de psicologia del trabajo: Aspectos psicosociales del trabajo (Vol. II, pp. 35-63). Madrid: Síntesis.

Sindicato dos Trabalhadores em Empresas de Prestação de Serviços de Asseio e Conservação e Limpeza Urbana de São Paulo. (2011). Perfil dos trabalhadores em asseio e conservação e limpeza urbana de São Paulo. São Paulo: SIEMACO.

Tajfel, H., \& Turner, J. C. (1986). The social identity theory of intergroup behavior. In S. Worchel \& W.G. Austin (Eds.), Psychology of intergroup relations (pp. 7-24). Chicago: Nelson-Hall.

Vazifehdust, H., \& Khosrozadeh, S. (2014). The effect of the organizational socialization on organizational commitment and turnover intention with regard to moderate effect carrer aspiration intention. Management Science Letters, 4(2), 277-286. doi: 10.5267/j.msl.2013.12.027 